\title{
Create Multi-Sided Platforms to Balance Demand and Capacity
}

\author{
Cameron Fisher \\ Massachusetts Institute of Technology, Cambridge, USA \\ Email: cafisher@mit.edu
}

How to cite this paper: Fisher, C. (2019) Multi-Sided Platforms Balance Demand and Capacity. American Journal of Industrial and Business Management, 9, 1596-1624. https://doi.org/10.4236/ajibm.2019.97105

Received: May 17, 2019

Accepted: July 27, 2019

Published: July 30, 2019

Copyright $\odot 2019$ by author(s) and Scientific Research Publishing Inc. This work is licensed under the Creative Commons Attribution International License (CC BY 4.0).

http://creativecommons.org/licenses/by/4.0/

\begin{abstract}
Technology advances continue to create opportunities to streamline business models. GPS, IoT and Cloud computing enable application development that features greater capabilities. By developing Multi-sided platforms, firms can better balance demand and capacity among buyers, suppliers and partners. Nurturing an asset-light ecosystem enables more direct, efficient and real-time commerce. The following study illustrates a path for growth by an incumbent operator. Balancing user requests versus enterprise capacity while bringing on-stream capital expenditures was never easy. Customer's dissatisfaction and profit setbacks often occur when consumption, production and fulfilment are out-of-balance until a stable equilibrium is determined. The quest to acquire customers and expand market share is prompting firms to innovate with a strategic digital platform to leverage new capabilities, efficiencies and insights. This paper offers a framework to improve business models that face hardships due to shifting customer preferences, popularity fads and mounting infrastructure investments.
\end{abstract}

\section{Keywords}

Cloud, ERP, GPS, IoT, Platform, RFID, Sensor

\section{Introduction}

To modernize their approach to managing a capital-intensive portfolio of fitness centers, the fictional Fitness World Inc. encounters many issues including:

- Peak periods of customer visits vary by urban and suburban locations

- Customer preferences difficult to forecast

- New entrants disrupt the competitive landscape

- Newest equipment and facilities are differentiators, but costly

As emerging capabilities in strategic digital platforms unfold, firms are scram- 
bling to stay ahead of new actors and concepts that threaten to disrupt current practices. This paper's scenario reflects that incumbent firms should recognize the need to respond or risk earning diminished returns in their future results. The study examines recent quantitative scholarly research and then offers design and development considerations to build such platforms. The scenario is simplified and disguised. However, the recommendations are based on real-life project experiences in industry settings.

The article is organized into the following sections:

1) Introduction

2) Literature Review

3) Definition

4) Illustrative Scenario

5) Current State

6) Assumptions

7) Guiding Principles

8) Stakeholders

9) Alternatives

10) Recommendations

11) Action Plan

12) Critical Success Factors

13) Conclusion

This study points out an approach for rallying resources and defining the necessary functionality to keep pace and stay relevant. The scenario contained in this article is based on an actual global organization. The mathematical equations are footnoted per scholarly research. However, many other characteristics and data are disguised and provided for illustrative purposes. The recommendations and action plans are likewise for illustrative purposes.

For example, Marriott chose to respond to Airbnb. Kroger chose to respond to Amazon and Blue Apron. "As a fan of Uber and Airbnb, I find the quality of service and value is better. The multi-sided rating system provides incentives for Uber drivers and Airbnb renters to provide good services because higher ratings can get them more businesses. At the same time, the passenger and tenant are motivated to behave so as to continue to enjoy cheaper, faster, and better services" [1].

For such sectors, business models are being re-invented and experimented, with a goal to retain hard-fought customers and producers. With some simplifying assumptions, this study examines building and operating a multi-sided market in a sector which seeks to embrace a range of advances including GPS, IoT, Cloud, Big Data and analytics.

\section{Literature Review}

A Pew Research Center report in 2016 determined 73 percent of Americans were not familiar with the phrase "sharing economy" as participation intensified 
(Smith, 2016) [2]. "There has been limited rigorous empirical research on multi-sided platforms or competition among them" (Evans) [3].

A collaborative peer-to-peer platform facilitates use of under-utilized inventory via matching/sharing for a membership and/or transaction fee. "A social movement can grow based on cooperative practices in the production and consumption of goods and services" (Zervas 2016) [4], and (Kenney, Zysman, 2016) [5].

A Sharing economy via digital platforms can reduce transaction costs for both consumers and producer to enable sharing of assets to be easier and less costly, leading to broader scale usage and enjoyment (Frenkel, Schor, 2014) [6].

If the asset (e.g. automobile, apartment, exercise equipment, etc.) is not in use, the platform can enable the owner and user to strike a transaction. If a home is idle, then Airbnb facilitates matching process for a percentage, and the resource owner generates revenue from an otherwise idle asset, which may or not be perishable (or an airplane seat). Owners derive returns from the idle resource with available capacity at a time that a customer desires the use.

"The relationship between price and cost is complex, and the simple formulas that have been derived for single-sided markets do not apply" [7].

\section{Definition of a Multi-Sided Platform}

A multi-sided platform for the purposes of this article is defined as a platform which enables interactions between participants to get the sides "on board", and appropriately charges each side. The platform services all sides to transact, match or auction available resources within a network of new and existing platform participants. The participants typically include consumers, providers and partners.

Platforms "must attract a large number of participants to both sides of the market, so that each participant has a substantial number of potential matches on the other side of the market. The value of the platform to a participant depends on the number of participants on the other side of the market, resulting in two-sided network effects.

The platforms' structure adds value by enabling transactions and matching different types of participants at a common meeting place with low friction. The platforms enable Airbnb, GrubHub, Lyft and the like and to transform hospitality and transport sectors by connecting producers, partners and consumers in new and efficient ways [8].

Multi-side platforms must enable potential transaction partners to search for one another, find a match, and complete a transaction. To be successful, a platform must reduce friction that otherwise would make transactions costly or more cumbersome" [9].

Uber and Airbnb exemplify "digital platforms which are multi-sided digital frameworks that shape the terms on which participants interact with one anoth- 
er". Some constraints occur within the user agreement restrictions. For example, Uber permits requesting a trip, but not selecting a specific driver. The system itself may not be changed by parties (e.g. riders, drivers, third parties). The participant profiles and platform algorithms determine the matchmaking.

A community or neighborhood of exchanged information is depicted in Figure 1 below. For example, TV networks and newspapers attract advertisers and viewers. Credit card systems attract merchants and cardholders. Stock exchanges attract buyers, sellers and listed corporate equities.

Our daily lives increasingly interact with a centralized computing capability that scales as volumes increase for data traffic of many sources and types. As shown in Figure 2 below, the endpoints can include phones, tablets, PCs, laptops, wearables and Internet of Things (IoT). For example, sensors on machines at a manufacturing plant can transmit vibration metrics as an early detector prior to failure.

As technology advances, improved functionality with efficient cost structures can be erected that draw from a multi-sided exchange. Early examples include printed newspapers that attract both advertisers and viewers. TV networks attract advertisers and viewers. Credit card networks attract merchants and cardholders. Stock exchanges attract buyers, sellers and listed corporations. Software producers attract both users and application developers which are vital to building out an eco-system.

A Bell Telephone manager observed the network effect as early as 1908 by noticing that the more users joining onto a telephone network, the more use and value occurs to each of the users [10].

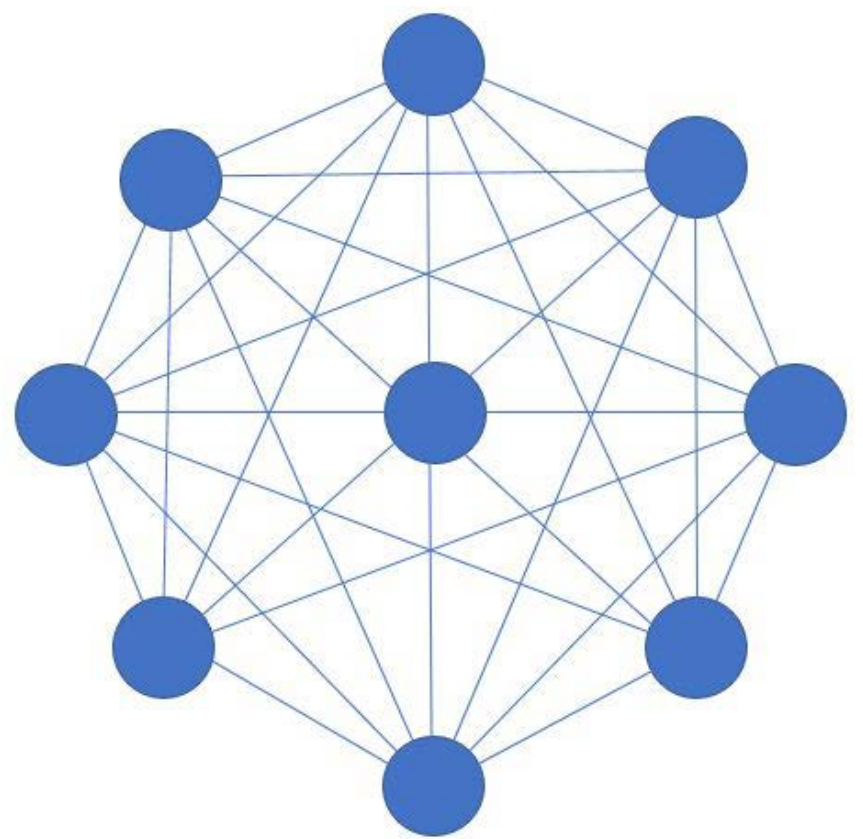

Figure 1. Network effect. 


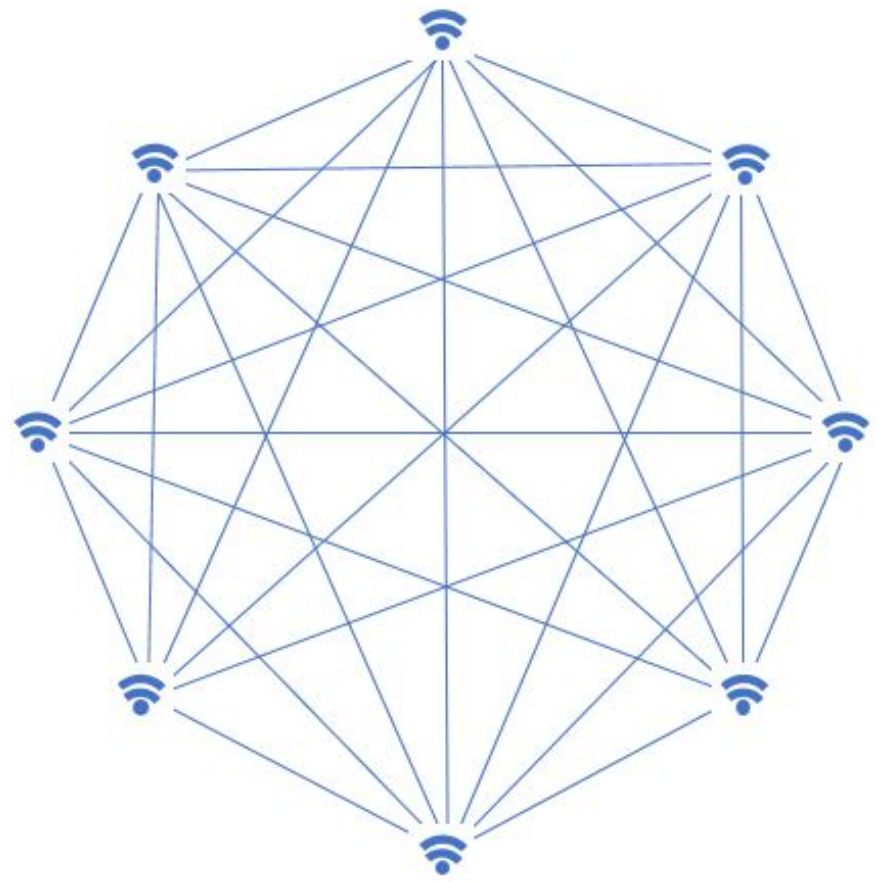

Figure 2. Technology-enabled performance.

Multi-sided platforms also offer central standards and quality control over the participants' experience. Although not perfect, signals and results are often far superior than traditional approaches. As observed by Adam Smith, the invisible hands will find an equilibrium and establish a balance better than a centralized manual planning approach.

"Multi-sided platform businesses serve distinct groups of customers and need each other in some way" [11].

The theoretical literature on multi-sided platforms has grown dramatically in recent years. Results and precision of findings vary based on industry, participants and complexity. With some assumptions on demand, cost, and indirect network effects, principles emerged that are insightful and useful.

Consider a platform as illustrated in Figure 3 that serves buyer groups A and $B$ [12]. If the platform raises pricing to group A members, fewer A's will join. If nothing else changed, the relationship between price and the number of A's would depend on the price elasticity of demand for A's. Since group B members value the platform more if there are more A's, fewer B's will join the platform at the current price for B's. A feedback loop exists. Once this effect is considered, the effect of an increase in price on one side is a decrease in demand on the first side because of the direct effect of the price elasticity of demand. The two demand functions would be:

$$
Q^{A}=D^{A}\left(P^{A}, Q^{B}\right) \text { and } Q^{B}=D^{B}\left(P^{B}, Q^{A}\right)
$$




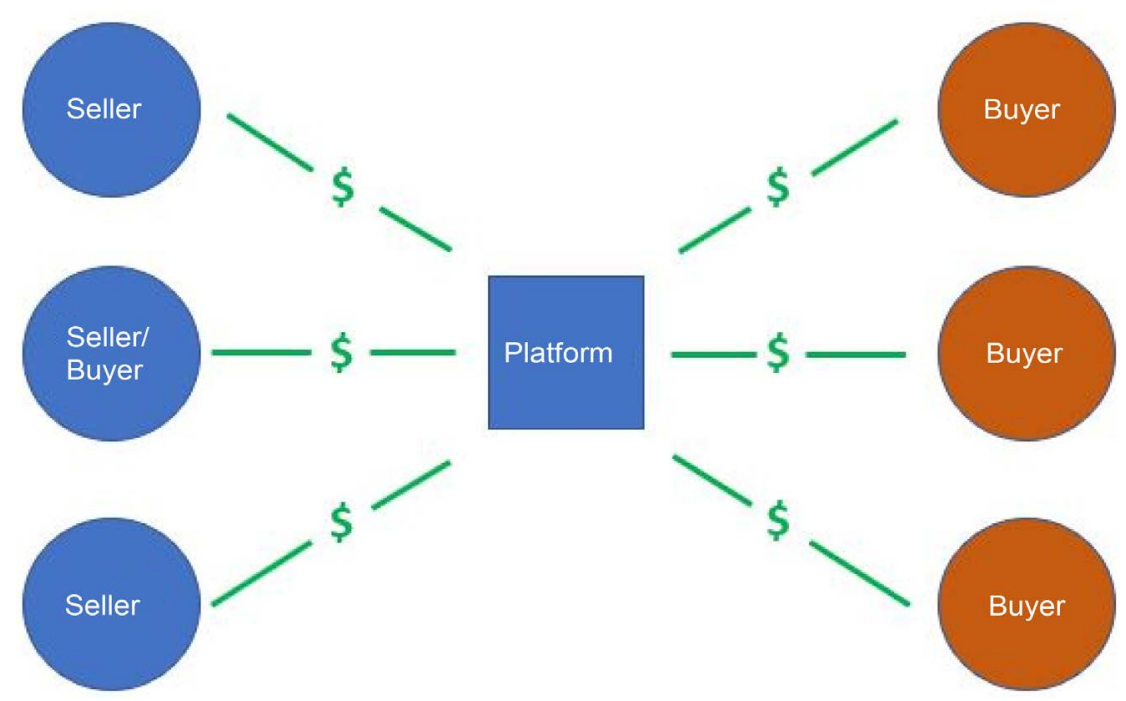

Figure 3. Multi-sided platform.

Let $e^{I}=-\partial D^{I} / \partial P^{I}\left(P^{I} / Q^{I}\right)$ for $I=A, B$

Let $\theta_{J}^{I}=\partial D^{I} / \partial Q^{J}\left(Q^{J} / Q^{I}\right)$ for $I, J=A, B, I$ not equal $J$

$$
E^{I}=-\left(\partial Q^{I} / \partial P^{I}\right)\left(P^{I} / Q^{I}\right) \text { for } I=A, B
$$

These elasticities correspond to the connectivity among the groups. Each side may be charged both a membership fee and a usage fee. Differentiating and solving for both demand functions for either price:

$$
E^{I}=e^{I} /\left(1-\left(\theta_{J}^{I} / \theta_{I}^{J}\right)\right) ; I, J=A, B, I \text { not equal } J
$$

Figure 4 Equation for converging responses and optimization [13].

The equation in Figure 4 illustrates the matching platform seeks out prices that maximize profits and the response sequences converge. For such platforms, the optimal pricing often depends on the price sensitivity of demand by the participants. The Lerner formula considers price cost margin equal to the inverse of the own-price elasticity of demand.

Exemplified by Mastercard on Visa platforms, "the collective setting of the interchange fee helped balance the demands between cardholders and merchants. It helped internalize an externality and eliminated the need for bilateral negotiations, reducing the transaction costs of internalizing the externality" [14].

For platforms in their earlier formative period, a complex relationship between price and cost could establish a profit-maximizing price for either side may be below the marginal cost of supply. Uber and Lyft offer special campaigns during introductory years where building adoption and scaling participant growth is a key goal. Depth in financial resources is necessary if short term profits were sacrificed in favor of special campaigns that build awareness and 
- Cycling Machines

- Stair-Masters

- Free Weights

- Showers

- Locker Rooms

- Classrooms

- Treatment Rooms

- Swimming Pools

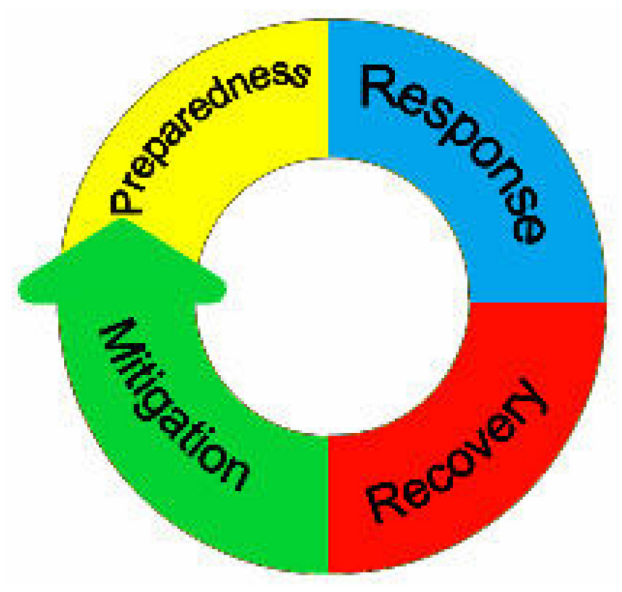

- Swimmers

- Aerobics

- Weight Loss

- Strength Builders

- Yoga Performers

- Kids Programs

- Senior Programs

- Maternity Programs

- Spa \& Wellness Programs

$\begin{array}{ll}\checkmark & \text { Demand } \\ \checkmark & \text { Capacity } \\ \checkmark & \text { Utilization } \\ \checkmark & \text { Queues } \\ \checkmark & \text { GPS } \\ \checkmark & \text { RFID } \\ \checkmark & \text { BYOD } \\ \checkmark & \text { URL } \\ \checkmark & \text { E-alerts } \\ \checkmark & \text { E-appointments } \\ \checkmark & \text { E-reschedules } \\ \checkmark & \text { E-cancellations } \\ \checkmark & \text { Loyalty Incentives } \\ \checkmark & \text { Gamification } \\ \checkmark & \text { Surge Pricing }\end{array}$

Figure 4. Dynamic demand and fulfillment platform for enterprise resource planning and reservations/appointments.

adoption. For example, $50 \%$ percent discount on the first 10 rides was a successful Lyft campaign in growing share and revenues. Such campaigns are accounted for in platform KPIs that emerged. These include KPIs for Margin, Scale, Momentum, Activity, Engagement, Retention, Customer Acquisition Costs, Customer Lifetime Value, ROI, etc.

For example, to determine Core Platform Contribution Margin, take Core Platform Contribution Profit (Loss) as a percentage of Core Platform Adjusted Net Revenue. This can be profit margin from all trips and delivery transactions. The Core Platform Net Revenue deducts costs such as marketing and R\&D expenditures. The result is "Core Platform Contribution Profit (Loss)", and then divided by Core Platform Net Revenue.

\section{Illustrative Scenario}

Fitness World Inc. faces new entrants leveraging emerging technologies to disrupt the established, capital intensive business model. New categories that are threatening include: 
- Mirror Interactive Home Gym

- Nordic Track

- Peloton Indoor Exercise Bike with Live-Video Connectivity and "luminary instructors"

A real-estate heavy, asset-intensive business model faces emerging threats on many fronts. From dumb-bells to smart assets, a major opportunity exists by matching exercise enthusiasts with fitness-related assets. Creating an asset-light platform can optimize:

- Participant Demand

- Resource Availability

- Asset Utilization and Capacity Management

- Real estate strategies

It is apparent to Fitness World that improved customer experience (delight) and cost-effectiveness is critical to customer growth, profitability and attracting supporters.

Currently, ongoing members and visiting guests are turned off by both unavailable assets and ignored assets. Depending on the season, locale, time-of-day, demographic profile and recent fads, it is difficult to plan or schedule the matching of participants to assets.

At other times, assets go under-utilized, need scheduled maintenance or incident-driven reactive maintenance. Suppose a visiting customer prospect tours the facility and sees older equipment ignored, and line-up queues for the popular new spinning cycle asset-the likelihood for sign-up can drop dramatically.

Multi-sided platforms are suited for markets in which two or more participants conduct interactions among end-users and try to get the multiple sides "on board" by appropriately charging each side. That is, platforms court each side while attempting to make money. Examples software producers court both users and application developers. TV networks and newspapers compete for advertisers as well as readers. Payment card systems need to entice and retain participating merchants as well as cardholders.

The range of variables that prompt an enterprise to design a platform to match fluctuating demand to capacity among participants is illustrated in Figure 4. The scenario identifies the following information flows and components:

A multi-sided market platform for GPS aware physical assets and human Resources (e.g. freelance counselors, at-home consultations, spa treatments) Capacity will enable Fitness World to reinforce core competency and barriers-toentry, while growing working capital and investors that can enhance digital eco-system investments.

The proven principles of ERP, CMMS (Computerized Maintenance Management Systems), Supply Chain Logistics, CRM, SEA (Sales Enablement Automation) are not all cutting edge. Leveraging these calculations is relatively straightforward. What is new: the convergence of GPS, Social, Analytics and Elastic Computing. 
By deploying a strategic digital platform, Fitness World can essentially build a moat around the core revenue-producing business while upgrading the digital eco-system for ongoing innovation and profitability. Already the NFL and NHL can embed radio emitters into players' shoulder pads. Therefore, Fitness World can build a framework to pursue similar innovation, as the affordability and reliability of IoT improve with Moore's Law.

By deploying a strategic digital platform to innovate people, process, technology and data, Fitness World can introduce new Yoga services and earn a fee more easily than Uber Eats can deliver a sandwich.

\section{Current State}

Regional Hubs in Northeast USA (New York, Boston, DC, Philadelphia, etc.) are shown in Table 1.

- 200 "brick and mortar" storefront locations

- \$600 Million annual Revenue

- Profile: 1000 Membership SKUs

- 200,000 Asset and Resource ID’s

- Sensors/RFID/IoT/GPS monitoring underway

The Fitness World network of clubs encounters diverse seasonality, peak periods and customer preferences due to different climates, demographics and urban/suburban locales.

Creating and managing a diverse catalog of products, services and providers is impossible to manage manually and using paper, spreadsheets and human phone calls.

\section{Assumptions}

The following assumptions apply to the illustrative scenario.

- Surge-pricing sends equilibrium-creating signals that influence participant behavior

- Notifications and alerts can be transmitted to listeners and subscribers with known elasticity

- Capacity planning and operations can comprehend these signals and allocation resources

- Queuing techniques and supply-chain algorithms optimize demand and capacity

- Membership growth and planned capacity affects resource planning and procurement decisions

- Access to capital via debt or equity is already stretched thin in past 30 years of growth

- Capital access is limited; debt capacity is limited; but proven business models can attract capital

- Underwriting by issuing equity is a possibility when business plans are viable

- Loyalty programs similar to Las Vegas Casinos, Airline and Credit Card programs can be integrated for points calculations and related ERP functions 
Table 1. Physical locations of Fitness World Inc. scenario.

\begin{tabular}{cc}
\hline Fitness World Brands & Qty \\
\hline New York World Club & 97 \\
Boston World Club & 33 \\
DC World Club & 10 \\
Philadelphia World Club & 5 \\
Jennifer Stevens Club & 26 \\
Finesse Club & 4 \\
Total Lady Gym \& Spa & 12 \\
Miami Sports Clubs & 7 \\
Christie's Fitness & 2 \\
Curves Fitness & 3 \\
Berlin World Club & 1 \\
Total & 200 \\
\hline
\end{tabular}

- Legacy Loyalty apps in existence will be easily de-commissioned or adapted

- Some standardization will improve efficiency

- $95 \%$ of current and prospective Sports participants use a smartphone

- A work location at midtown has more use during lunch and $5-7 \mathrm{pm}$. A suburban location is busier before/later or weekends

- Wide range of group exercise and fitness programs will continue including assets as racquet courts, pools, basketball courts, strength training equipment, cardiovascular machines and other exercise equipment

- Higher margins on services such as beauty, spa and personal training could be emphasized

- Sports clinics for Kids (aka Daycare) may be considered

\section{Observations}

During exit interviews with customers, a large percentage cancelling membership cite equipment availability as a major factor to membership termination:

- Is that the actual reason, or just a convenient explanation

- The user persona and customer journey need to be decomposed and understood by marketers

- Further research and Product concepts/research should continue as tastes or preferences may be a fad such as Low carb, Muddy Warrior, American Gladiators, etc.

- Increased budgeting on Market Research and Pragmatic Product Marketing will yield decision making that is fact-based not "gut-driven"

- Budgeting for reliable customer and product research is a success factor

- Expensive real estate is considered a constraint; creative alternatives exist that 
are more asset-light requiring less onerous levels of working capital

- Example: Route a fitness advisor to a customer's home, work or outdoor location where both parties see GPS progress to coordinate their meet-up with fewer cancelled appointments and easier re-scheduling

- Arranging a therapeutic masseuse or nail care appointment at a customer's home or work location is significantly less asset-intensive and attracts higher profit margins

- The "gig economy" also known as the "sharing economy" can schedule and fulfill a multi-sided spa treatment as easily as Uber Eats handles lunch

- Digital advertising agencies can influence buyer behavior via better advertising, campaigns and user interface designs

- What about the members that are retained? What is important to them? A newly "joining" member may have different motivations than a recent or long-term participant

- Better use of customer surveys and notifications will enable more informed analytics and decision making

\section{Guiding Principles for Building Platform Solutions}

To develop and deploy a multi-sided platform, establishing guiding principles such as the following will help set the direction for creating a cohesive team:

- Asset Light

- Minimized Working Capital

- Machine Learning

- Network Node Support

- Location Aware

- Sensor Monitoring

- In some cases, a fast-follower will outperform a first-mover for long term viability

\section{Platform Design Principles}

- Establish a single source of the truth

- Minimum viable product delivers speed-to-value and time-to-market

- Minimize quantity of interfaces

- Safeguard data with access controls

- Platform foundation to be open for 3rd Party Vendors (After MVP)

- Design with user experience in mind

- Constant feedback including prototyping

- Consider future phases when designing

- Consider the impact of complexity on performance

\section{Stakeholders}

\subsection{Market Analysis}

According to International Health, Racquet and Sports Club Association, the 
U.S. health club industry posted growth in revenue, memberships, and quantity of club locations:

- U.S. revenue grew to $\$ 30.0$ billion in 2017 from $\$ 27.6$ billion in 2016

- U.S memberships increased to 60.9 million in 2017 from 57.2 million in 2016

- U.S. club count rose to 38,477 sites in 2017 from 36,540 sites in 2016

- 1 out of 5 Americans belonged to at least one U.S. health club or studio since 2008

- Membership has grown by $33.6 \%$

- Total quantity of club-goers has increased by $31.5 \%$

- Total quantity of club visits has increased, from 4.3 billion visits in 2008 to 5.9 billion in 2017

- Ancillary services and new product introductions offer potentially higher growth and margins

\subsection{Competitor \& Threat Analysis}

- Fitness World enjoys leading market position using leading branding and offerings

- Regional clustering strategy provides benefits to members for convenience and variety

- Size and scale advantageous partnerships, including third-party vendors and suppliers

- Model enables scaling more rapidly than competitors to keep pace with new trends and preferences

- Efficiencies via scaling fixed costs (e.g. procurement, marketing, membership campaigns, labor relations, etc.)

- Expertise in site selection and negotiation of lease and acquisition terms to ensure that a location meets criteria

- Barriers of entry are significant in urban regions where increased financial and other strengths allow build-out of adaptive pricing, and marketing

- Improve financial performance by expense control, operational efficiencies, technology and labor planning

- Smaller or nimble entrants could leverage disruptive technologies quickly

Innovators Dilemma: Established Market leaders are allegiant to traditional customers for the bulk of revenues. The Incumbents Path to New Growth often requires breakthrough strategies and execution.

\subsection{Current Competitors}

- YMCA/YWCA

- Gold's Gym

- Jenny Craig

- Weight Watchers

- Cosmetic clinics, surgeries, spa's

- Golf Clubs, Squash Clubs 


\subsection{New Concepts and Competitors}

- Bio-metric Smart Watch

- Nordic Track

- Home-based 'Mirror Interactive Home Gym'

- Peloton Indoor Exercise Bike with Live-Video Social connectivity and luminary instructors

- GPS Dispatched-Home Counselors, Yoga, Masseuse, etc.

- Smart Automobiles with vibrating interior cabins, etc.

Stakeholder Analysis-Fitness World Inc.

Executive leadership at Fitness World has determined that overall goals and corporate objectives include: "To uncover growth opportunities, reduce operating costs, improve margins, and optimize."

Potential sources for such improvements occur from many sources including:

- Revenue Enhancement (e.g. Volume, Mix, Rates)

- Cost Reduction and Cost Avoidance (e.g. promotional spending, reduced liability, etc.)

- Employee Morale, Partner Morale and Productivity

- Compliance (including penalty avoidance)

- Return on Assets Employee and Return on Invested Capital

- Growth through acquisitions

- Membership and subscription growth

- Group exercise classes attendance, capacity utilization

- Class satisfaction reviews and surveys

- Top of the line and modern equipment in good working condition

- Pools and tennis courts in the price of certain memberships, when available

- Pricing adjustments in order to increase revenue while also drive membership growth

- Grow ancillary and other non-membership revenues

- Grow ancillary and other non-membership revenues

- Multi-session personal training membership product and fee-based

- Sports Clubs for Kids programs (e.g. while parents at work, or appointments)

- Optimization of clubs and profit margins

- Club closures when appropriate to sustain consistent quality and modernization standards

- Fitness World demonstrated commitment to increase the quality of the member experience, and thereby increase net membership growth, conversions and reduced churn

- To better measure the member experience, social media and other analytics/metrics help analyze the areas can improve upon as well as the areas to keep existing, and attract new/existing enrollments and renewals

The revenues for the scenario during 2018 are shown in Table 2. Stakeholders include Chief Membership Officer, Chief Financial Officer, Chief Counselor Officer, Chief Product Officer, Chief Membership Programs Officer. 
Table 2. 2018 revenue by line of business for Fitness World Inc.

\begin{tabular}{ccc}
\hline & \multicolumn{2}{c}{2018} \\
\cline { 2 - 3 } & \$ Million & $\%$ \\
\hline Membership Revenue & 643 & 100.0 \\
Personal Training Revenue & 173 & 19.8 \\
Other Ancillary Club Revenue & 56 & 5.9 \\
Fees and Other Revenue & 11 & 1.3 \\
Non-Membership Revenue & 240 & 27.1 \\
\hline
\end{tabular}

Customer Satisfaction Metrics:

- Net Promoter Scores about Fitness World offerings

- Media impressions, Social Media Activity

- Membership Attrition

- Membership Renewals

- Geography footprint

- Safety, Compliance, Product Liability

- Asset Utilization, Return on Assets Employed, Return on Investment, IRR, NPV, Payback

- Volume, Mix, Rate, Margin, etc.

Stakeholder: Platform Provider

- Net Promoter Scores about offerings

- Market Share

- Share of Wallet

- Buyer \& Seller Testimonials

- Platform Revenue Growth

- Investor Interest

- Employee Turnover

- Media impressions, Social Media Activity

- Client Referenceability

- Client Testimonials

- Account Profitability

- Roadmap, Business Development

- Technology Footprint

- Partner Relationships

- Employee Morale

- Profit Gains, Client Retention Rates

- Revenue Growth

- Profit Growth

- Competitor Share

- Geographic footprint

- Membership fees 
- Utilization

- Transaction Volume

- Average Order Value

- Average Partner Order Value

- Return on Assets, Volume, Mix, Rate, Margin, etc.

- Owners and Principals

\subsection{Current State Process Flows}

Current state information flows, functions and actors are illustrated in Figure 5. The business model has not yet been streamlined prior to the introduction of the multi-sided platform for the Fitness World scenario.

\section{Alternatives}

A range of alternatives are deemed out of scope for this study, including:

- Seek a Merger

- Seek to be Purchased

- Focus spending programs on acquisitions

- Divert more capital to International Expansion

- Latin America

- Europe

- Asia

- Combinations of the above instead of strategic digital platform investment Per direction of the Board of Directors and CEO sponsors at Fitness World,

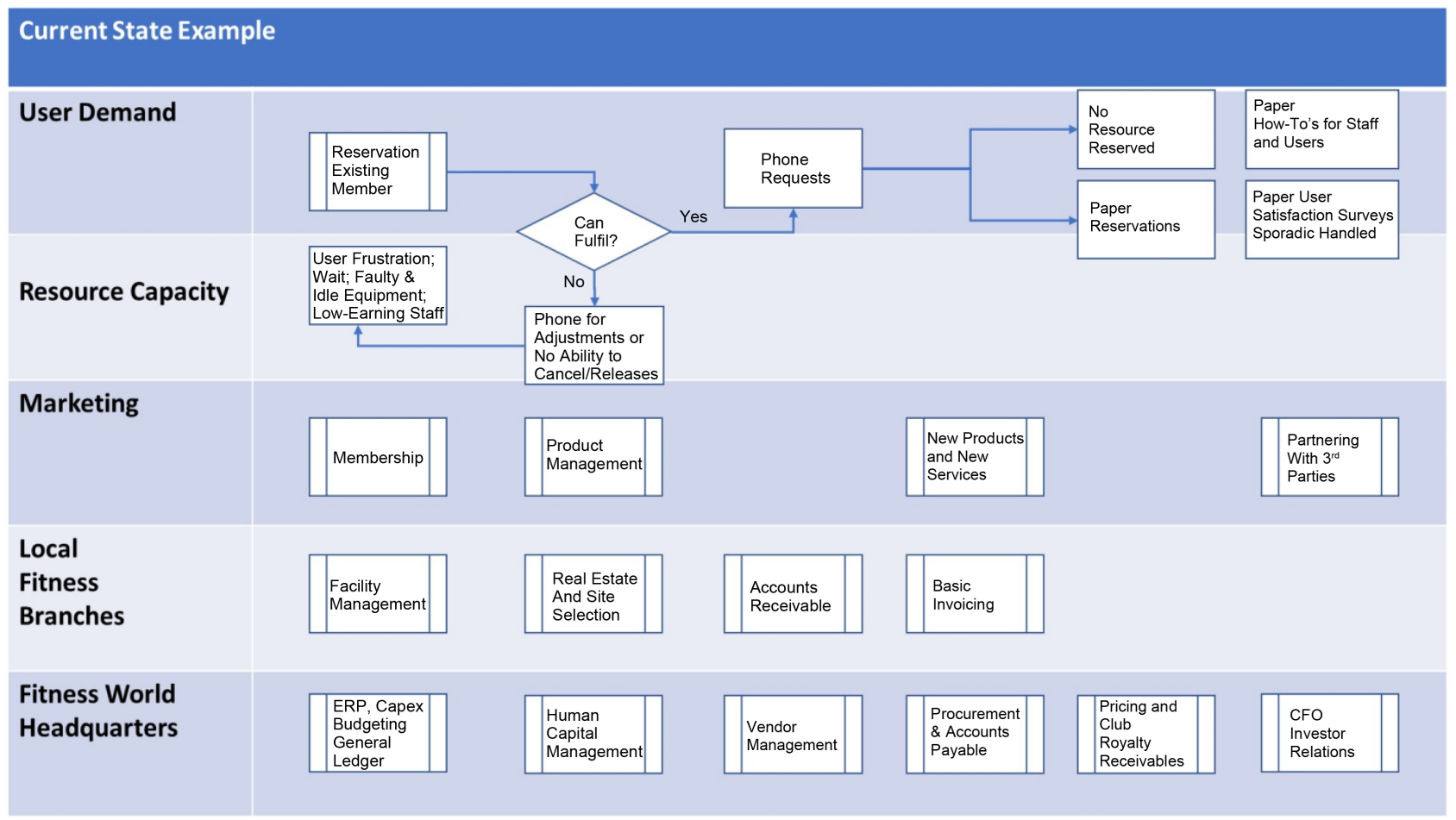

Figure 5. Current state process flows for Fitness World Inc. 
the commitment to increased levels of investment and efficacy of the digital eco-system will be a primary focus of new program initiatives with technology and business partners. Merger and acquisition activity can be managed separately, in parallel or opportunistically. The capital plan will affect the capital and operating budgeting and is outside the scope of this analysis.

\section{Recommendations}

A multi-Sided marketplace and platform solution: Buyer seeks timely replenishment with best satisfaction/delight and pays the platform; MobileRep seeks the closest Buyer with the best Margin on prioritized call list.

The Platform helps incentivize and optimize MobileAgent by Minute, Mile and OutcomeQuality (Customer Rating, Wait time, etc.).

In contrast to the above, the target state To Be Process Flows show increased automation, GPS aware sensors and behavior-driven feedback mechanisms. A Cloud based computing platform provides scalable elastic computing to realize surge-demand performance and reliability [15].

User profiles, API integrations, analytics and enhanced UX produce more satisfied members and cost-effective resource planning/consumption.

The use of alerts, notifications, cancellations, e-Reservations and e-Appointments (e.g. eMail, texts, robo-calls, contact centers) means that consumers, as well as providers, are achieving better use of time and better asset utilization.

The open DSP accommodates an eco-system of growing supply-based which can respond to surge-pricing or other peaks and valleys induced by internal and external market forces [16] [17].

\subsection{Future State Process Flows}

Target State information flows, functions and actors are illustrated in Figure 6. The business model has been streamlined by introducing a multi-sided platform for the Fitness World scenario.

- "Uber-Style" Connection of Request with (stationary or mobile IoT-enabled Demand and Capacity matching of requests and resources)

- RFID in sweatband shows locations and activity of members and visitors

- Similar to submitting a points bid for the matching of most popular college course offerings and professors

- Similar to airline Reservation system whereby pricing is costlier closer to actual capacity expiration time and costlier during peak periods where demand exceeds the capacity

- GPS tracking and status alerts enable fewer missed appointments and better attendance

- Resource Request-fulfill from existing Inventory or (batch) Issue Order Plan to Procure or capex

- Loyalty rewards = gamification of participation and segmentation strategies MobileAgents manages daily activities using algorithm-driven business rules 


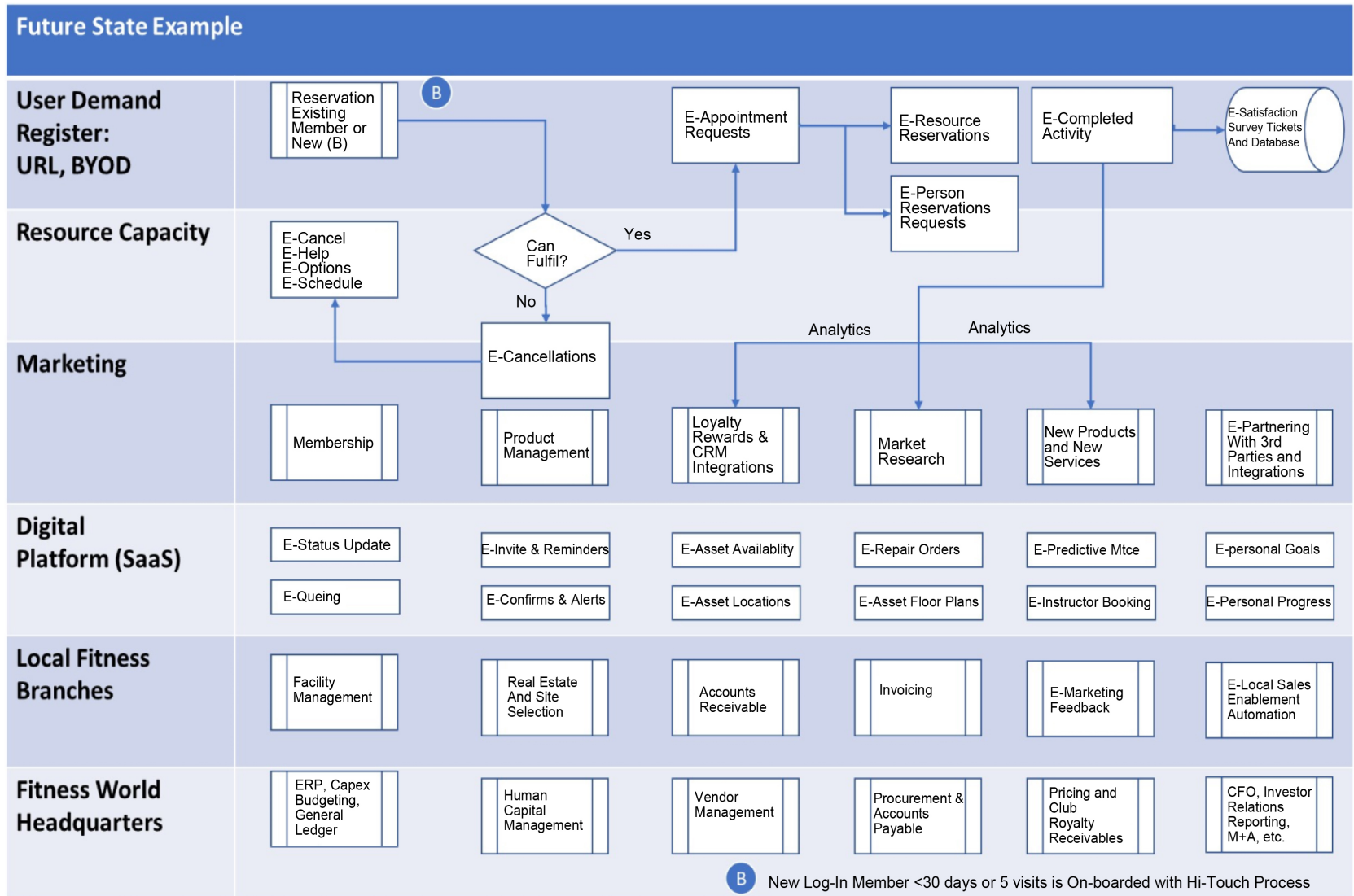

Figure 6. Platform enabled future state process flows for Fitness World Inc.

to focus on: Scheduling, inventory management, inventory transfers, placing sales orders, placing invoices fulfilled from the optimized supply chain node.

- MobileAssets placing returns and credit memos, log transaction times and mileage, etc.

- MobileAgents and Mobile Assets in a company-provided Vehicle, or Independent Contractor on a Scooter or Authorized Re-seller in a GPS enabled Van, GPS dispatched human coach/aesthetician or mobilized "Gym in a Truck". Different routing rules for commissions, SLAs, OLAs, settlement, etc.

- MobileReps are offered training, asset maintenance, financial literacy learning, instructional video libraries, etc. to foster and evangelize a growing network of nodes and participant health/satisfaction/retention/cross-sell/up-sell opportunities.

- The multi-sided rating system incentivizes consumers and providers to behave because higher ratings can get them selected first over lower rated participants.

- Uber and Airbnb do not collect upfront fees from customer or service provider. In the Fitness World example, new services such as yoga and manicure would collect a percentage of the price only when demand and supply are matched. For health clubs, a monthly membership subscription is often col- 
lected. Rather than rely solely on a flat fee, users booking a Stairmaster at a specific date/time can use points within the multi-sided platform to allocate and consume scarce resources. Combinations of points plus dollars can also be a source of new revenue.

\subsection{Architecture}

The design of the application can use a prioritization scheme as shown in Table 3. The combination of a loyalty program with a resource optimization platform and gamification can help balance demand and capacity for the scenario.

The design of the application can use a capacity scheme as shown in Table 4. The resource planning for optimizing available resources and balancing demand can improve the user experience and minimize delays for the scenario.

Table 3. Illustration of incentivized and gamified demand and capacity application interface.

\begin{tabular}{cc}
\hline Usage Monitoring and Tracking enables Surge Pricing, Loyalty Programs and Gamification \\
\hline Points Awarded for Advanced Reservations... & \\
\hline 14 days in Advance or earlier & 1400 \\
7 Days in Advance & 700 \\
6 Days in Advance & 600 \\
5 Days in Advance & 500 \\
4 Days in Advance & 400 \\
3 Days in Advance & 300 \\
2 Days in Advance & 200 \\
1 Days in Advance & 100 \\
2 hours in Advance & 0 \\
Access Resource Immediately & -100 \\
\hline
\end{tabular}

Table 4. Illustrated UI for asset and resource reservation planning application interface.

\begin{tabular}{|c|c|c|c|c|c|}
\hline & & & A & B & A-B \\
\hline $\begin{array}{c}\text { Advanced Resource } \\
\text { Request }\end{array}$ & $\begin{array}{l}\text { City: } \\
\text { Boston }\end{array}$ & $\begin{array}{c}\text { Month } \\
\text { Day } \\
\text { Time }\end{array}$ & $\begin{array}{c}\text { Inventory } \\
\text { Max } \\
\text { Capacity }\end{array}$ & $\begin{array}{l}\text { Inventory } \\
\text { In Use }\end{array}$ & $\begin{array}{l}\text { Inventory } \\
\text { Available }\end{array}$ \\
\hline \multicolumn{6}{|l|}{ Resource } \\
\hline -Cycling Machine & & & 24 & 21 & 3 \\
\hline -Stair-Master & & & 30 & 23 & 7 \\
\hline -Free Weights & & & 100 & 40 & 60 \\
\hline -Shower & & & 36 & 24 & 12 \\
\hline -Pool Lane & & & 12 & 8 & 4 \\
\hline -Classroom Seats & & & 14 & 11 & 3 \\
\hline- Spa & & & 6 & 4 & 2 \\
\hline -Counselor & & & 8 & 5 & 3 \\
\hline
\end{tabular}


Resource N: (Equipment, Classroom, Counselor, etc.) for 24 hours $\times 7$ days.

The development of the application can use a calendaring algorithm as shown by Table 5 . The logistics for optimizing available resources and balancing demand can maximize the user experience and reduce cancellations or excess enrollments for the scenario.

Digital Commerce and Platform design factors will consider:

- Quote and Convert to Sales Order; and Invoice upon Customer Approval

- Credit Memo/Return to Inventory (from purchasing member);

- Users receive goods from customer back to the MobileAsset

- Receive goods (from Inventory or Warehouse to MobileAsset)

- Return goods to warehouse

- Cycle counts/stock count/adjust inventory

- Pricing: for every line order

- MobileRep role-based privileges permit modifying prices. If proposed below a defined threshold, transaction held for ManagerRole (e.g. email, text, release code, etc.)

- Platform calculates margin, and profit for each line and for the entire transaction based on formula associated to SKU, Customer ID, Campaign ID, etc.

- Transactions run multiple parameters for: total quantity, number of lines, total amount, discount/free items, commission, campaign, etc.

- Each transaction line can be addressed for a different display guideline (with optional Instructional Video) per customer location

- Order summary provides sub totals for each grouping attribute

- Invoicing and order notifications sent to buyers/sellers automatically

- Platform alerts users when buyer exceeds credit limit or is already on Hold

- Data exported/imported leveraging existing ERP investments (Service, Finance, SFA, etc.)

- SKUs, Customers, Contacts, Price Levels, Sales Orders, Invoices, Credit Memos, Inventory transfers (goods into MobileAsset)

Table 5. Illustrated UI for asset and resource appointment scheduling application interface.

\begin{tabular}{|c|c|c|c|c|c|c|}
\hline Sun & Mon & Tue & Wed & Thu & Fri & Sat \\
\hline \multicolumn{7}{|l|}{ HH:MM } \\
\hline HH:MM & Reserved & & Reserved & & Reserved & Reserved \\
\hline$\ldots$ & & & Reserved & & Reserved & \\
\hline$\ldots$ & & & & & Reserved & \\
\hline $\mathrm{HH}: \mathrm{MM}$ & & Reserved & & & & \\
\hline HH:MM & Reserved & & & & Reserved & \\
\hline \multicolumn{7}{|l|}{ HH:MM } \\
\hline HH:MM & & & Maintenance & & & Maintenance \\
\hline HH:MM & Closed & Closed & Closed & Closed & Closed & Closed \\
\hline
\end{tabular}


- Debts and customer balance (Open Fitness World member account invoicing, payment, etc.)

- Platform plans routes based on customer location and customer parameters such as purchasing member's visit frequency

- Last visit date updated

- Account preferred visit dates

- Next Expected visit updated based on visit frequency and last visit date

- Other account or asset parameters (size, type, vertical, revenue, credit status, location, etc.)

- Planned events appear on MobileRep calendar and personal activity plan

- Address workflow, orders from warehouse, invoices fulfilled and credit memos

- Route and Activity planning

- Merchandizing activities

- Sensors transmit updates for Inside/Outside temperature, humidity, precipitation, circuitry health, statuses, variances according to business rules

- Recommendations are based on a given formula based on existing or integrated data

- Collect credit card payment using 3rd-party payment gateway (Visa, Zelle, Stripe, Venmo, Libra, etc.)

Metadata and technical factors will consider:

- Availability, Reliability, System Performance, Security, MTTR, MTBF, RPO, RTO

- Analytics and statistics, dashboards and reports

- Regular dashboard and portfolio snapshot updates

- Competitive Bid process among contending hardware, software, services suppliers

- Enlisting industry luminaries to define strategic factors and execution

- Negotiate best in Class Pricing, Partners, Terms, Conditions, SOWs, Support, Training

- Negotiate Platform License Pricing model and Azure/AWS/GCP to revised privileges and cost arrangements, based on growing adoption, business rules and solution roadmaps

- Process flows, use cases, and a web-site logistics console compatible with form factors, OS, BYOD

\subsection{Requirements Elicitation Principles}

During the design phases when stakeholders and subject matter experts are being interviewed, it is helpful to adhere to guiding principles. Principles useful for eliciting requirements are outlined in Table 6 for the scenario.

\section{Action Plan}

To execute the recommendations to design and build the multi-sided platform 
Table 6. Requirements elicitation principles.

\begin{tabular}{|c|c|}
\hline Principle & Details \\
\hline Completion & - Establish complete end to end processes across departments \\
\hline & - Establish 1-method to perform each task \\
\hline Simplification & - Decrease the total steps in each task \\
\hline & - Minimize the interfaces required for each task \\
\hline & - Safeguard data with suitable access controls \\
\hline Collaboration & $\begin{array}{l}\text { - Establish a "single source of the truth" } \\
\text { - Set the foundation for collaboration and cross-selling }\end{array}$ \\
\hline User Adoption & $\begin{array}{l}\text { - Design with user experience in mind } \\
\text { - Constant feedback }\end{array}$ \\
\hline Proactive & $\begin{array}{l}\text { - Design with the end in mind } \\
\text { - Consider future phases when designing } \\
\text { - Will today's efforts support direction refined tomorrow? }\end{array}$ \\
\hline $\begin{array}{l}\text { Configuration (Not } \\
\text { Customization) }\end{array}$ & $\begin{array}{l}\text { - Make future upgrades easier } \\
\text { - Use minimal viable product initially to launch faster } \\
\text { - Consider the impact on performance }\end{array}$ \\
\hline
\end{tabular}

solution for the illustrative scenario, an action plan is outlined below.

\subsection{Requirements Definition Plan}

During the design and development phases, the requirements definition plan will define tasks that reflect known pre-requisites and dependencies. Steps 1 through 10 is outlined in Table 7 for the scenario.

Several useful metrics and KPI's can be established to monitor the management of scope, costs, schedule and quality assurance including:

Quantitative Metrics for Development Activity include:

- Story Count

- Story Effort Estimates

- Backlog

- Module Count

- API Count

- FRICE (Forms, Reports, Interfaces, Conversions, Enhancements)

- Test Plan Count

- Change Request Count

- Resource FTEs

- Resource FTE Utilization

- Resource FTE

- Actual vs Plan Variances

- Test Scripts per Plan Count

- Regression testing, UAT, SIT

- Defects

- Rework

- Velocity

- Approver Sign-Offs Complete 
Table 7. Requirements definition plan.

\begin{tabular}{|c|c|c|c|c|}
\hline$\#$ & What & Where & When & Who \\
\hline 1 & $\begin{array}{l}\text { Preparations for Fitness } \\
\text { World Requirements } \\
\text { Kick-Off }\end{array}$ & Virtual & $\begin{array}{l}\text { Prior to } \\
\text { Requirements } \\
\text { KickOff }\end{array}$ & $\begin{array}{l}\text { Project Manager, } \\
\text { Business Analyst } \\
\text { (BA) }\end{array}$ \\
\hline 2 & Communications Plan & Virtual & $\begin{array}{l}\text { After Project } \\
\text { Set-Up }\end{array}$ & $\begin{array}{l}\text { Sponsors, Project } \\
\text { Manager, BA }\end{array}$ \\
\hline 3 & $\begin{array}{l}\text { Requirements Phase } \\
\text { Kick-Off }\end{array}$ & On Site & Milestone Event & $\begin{array}{l}\text { All Stakeholders } \\
\text { Project Director } \\
\text { Project Manager } \\
\text { BA, Vendor Prof } \\
\text { Svcs }\end{array}$ \\
\hline 4 & User Survey & Web Survey Tool & Prior to Elicitation & Key Users \\
\hline 5 & $\begin{array}{l}\text { Requirements Elicitation } \\
\text { Phase }\end{array}$ & $\begin{array}{l}\text { Sessions depend } \\
\text { on scope, } \\
\text { complexity, } \\
\text { interfaces, gaps }\end{array}$ & Underway & $\begin{array}{l}\text { Key Users, SME's, } \\
\text { BA }\end{array}$ \\
\hline 6 & -Session 1 & JAD & After Survey & $\begin{array}{l}\text { Key Users, SME's, } \\
\text { BA }\end{array}$ \\
\hline 7 & -Session 2 & Brainstorm, Collab & After Session 1 & $\begin{array}{l}\text { Key Users, SME's, } \\
\text { BA }\end{array}$ \\
\hline 8 & -Session 3 & $\begin{array}{l}\text { Validation, Group } \\
\text { Presentation }\end{array}$ & After Session 2 & $\begin{array}{l}\text { Key Users, SME's, } \\
\text { BA }\end{array}$ \\
\hline 9 & Requirements Issued & Sign-off & Milestone Event & $\begin{array}{l}\text { Project Manager } \\
\text { Project Sponsor } \\
\text { Key Users } \\
\text { BA }\end{array}$ \\
\hline 10 & $\begin{array}{l}\text { Agile Configuring, } \\
\text { Prototyping, Use Case } \\
\text { Demonstrations, } \\
\text { Backlog, MVP, } \\
\text { Dev-Test-Stage-Prod } \\
\text { regions, etc. }\end{array}$ & $\begin{array}{l}\text { Project Team } \\
\text { location or Webex }\end{array}$ & $\begin{array}{l}\text { After Require- } \\
\text { ments Sign-off }\end{array}$ & $\begin{array}{l}\text { Key Users, SME's, } \\
\text { BA }\end{array}$ \\
\hline
\end{tabular}

\section{- Approver Sign-Offs Outstanding}

Qualitative Assessments for Development Activity include:

- Retrospectives

- Prototyping Sessions Feedback

- Compilation of Lessons Learned

- Repository of Lessons Learned

\subsection{Project Plan}

During project management activities, the task definitions will comprise a project plan that reflects known pre-requisites, dependencies and milestones. Steps 1 through 16 are outlined in Table 8 for the scenario.

\section{Critical Success Factors}

Factors that are critical to the success of the project initiative include: 
Table 8. Project plan.

\begin{tabular}{|c|c|c|c|c|c|c|c|c|c|c|c|c|c|c|}
\hline ID & Task & Resource & Pre-Req & Start & End & Stakeholders & \multicolumn{8}{|c|}{ Sprint \# } \\
\hline & & & Period: & & & & 1 & 2 & 3 & 4 & 5 & 6 & 7 & 8 \\
\hline 1 & $\begin{array}{l}\text { SOW Create, } \\
\text { Review }\end{array}$ & $\mathrm{PM}, \mathrm{BA}$ & & $1 / x x / x x$ & $1 / x x / x x$ & & & & & & & & & \\
\hline 2 & $\begin{array}{l}\text { Team Member } \\
\text { Training }\end{array}$ & PM, BA & & $1 / x x / x x$ & $1 / x x / x x$ & & & & & & & & & \\
\hline 3 & $\begin{array}{l}\text { Prep, Project } \\
\text { Kickoff }\end{array}$ & $\mathrm{BA}, \mathrm{PM}$ & & $2 / x x / x x$ & $2 / x x / x x$ & & & & & & & & & \\
\hline 4 & Functional Reqmts & $\mathrm{BA}$ & & $2 / x x / x x$ & $3 / x x / x x$ & & & & & & & & & \\
\hline 5 & Technical Reqmts & $\mathrm{BA}, \mathrm{EA}$ & & $2 / x x / x x$ & $3 / x x / x x$ & & & & & & & & & \\
\hline 6 & Architecture & EA & & $3 / x x / x x$ & $4 / x x / x x$ & & & & & & & & & \\
\hline 7 & Design & $\mathrm{BA}, \mathrm{D}$ & 4 & $3 / x x / x x$ & $4 / x x / x x$ & & & & & & & & & \\
\hline 8 & Agile Configure & PM, EA, DV & & $4 / x x / x x$ & $6 / x x / x x$ & & & & & & & & & \\
\hline 9 & UAT & $\mathrm{BA}, \mathrm{DV}$ & & $4 / x x / x x$ & $6 / x x / x x$ & & & & & & & & & \\
\hline 10 & SIT & $\mathrm{BA}, \mathrm{EA}, \mathrm{DV}$ & 9 & $4 / x x / x x$ & $6 / x x / x x$ & & & & & & & & & \\
\hline 11 & Staging/Prod'n Env & PM, EA & & $5 / x x / x x$ & $5 / x x / x x$ & & & & & & & & & \\
\hline 12 & Train Trainers & $\mathrm{PM}, \mathrm{BA}$ & & $6 / x x / x x$ & $7 / x x / x x$ & & & & & & & & & \\
\hline 13 & Train Users & $\mathrm{BA}$ & 12 & $6 / x x / x x$ & $8 / x x / x x$ & & & & & & & & & \\
\hline 14 & Go-Live MVP & $\mathrm{PM}, \mathrm{BA}$ & & $6 / x x / x x$ & $6 / x x / x x$ & & & & & & & & & \\
\hline 15 & $\begin{array}{l}\text { Trnsfr to } \\
\text { Ops/Support }\end{array}$ & EA, PM & 14 & $7 / x x / x x$ & $7 / x x / x x$ & & & & & & & & & \\
\hline 16 & $\begin{array}{l}\text { Enhancem'ts/ } \\
\text { Upgrades }\end{array}$ & BA, SUP & 14 & $8 / x x / x x$ & $8 / x x / x x$ & & & & & & & & & \\
\hline
\end{tabular}

- Responding to changing market conditions and evolving customer preferences

- Engaging Opinion Leaders and Influencers

- Accessing Technology Talent than can Execute

- Agile and Deliberate Release Management

- Controlling Scope, change orders

- Performing proactive organizational change management

- Managing Resources, including Capital, Managerial, Technical, Marketing, Operations

\subsection{Risk Mitigation}

Throughout the project initiative, the project team will take measures to identify risks and manage arising issues. The risks identified early that will require mitigation include: 


\subsection{Known Unknowns}

- Impact $\times$ Probability $=$ Urgency

- Ambitions and expansion plans of mega-Competitors (Facebook, Apple, Alphabet, Netflix, Uber)

- Customer preferences for At-home exercise versus On-premise brick and mortar experiences

- Ability of Fitness World to foster: "Meet a new friend and socialize" to augment visits, experiences and social media campaigns

- Positioning and segmentation of customer and prospective customer spending trends

- Labor relations and recruiting implications of e-Matching resources and users

\subsection{Unknown Unknowns}

- Virtual reality

- Artificial Intelligence

- Leapfrog Entrants

- Governance and Compliance

- Data Confidentiality and GDPR

It is known that failure to address risks early can prove costlier if postponed to later in project. Risk = uncertainty, and risk management can increase the probability of project success by minimizing negative risks and increasing positive eventualities.

The risk appetite of Fitness World is not fully known which can influence planned or reactive responses to scope creep if stakeholder aims to expand vision; or schedule flaws, employee turnover, conflicts in deliverable specifications, or impaired worker productivity due to personal, political, legal, technical, complexity or ambiguous elements.

When dealing with Negative Risk Strategies, the choices include eliminate, avoid, transfer, outsource, warranty, insurance. Mitigation can be pursued by testing or redundancy. Knowing the sponsor vision and commitment will sometimes enable escalations of risks to an appropriate party. Sharing risk with contractors, vendors or joint venture will also distribute some risk. According to the lessons of "The Mythical Man Month", adding resources to deal with an emergence of project problems can actually worsen progress and add to complexity and risk. Agile sprints and a prioritized backlog are methods used to deal with project complexity, rapidly changing market conditions and aggressive timelines.

\subsection{Deliverables}

Examples of deliverables are shown below for the multi-side platform scenario.

Fitness center self-service system: To improve customer experience by decreasing wait times at service counters, a self-service system allows members to 
use a membership card to access their online account, workout schedule, register for classes and send payments. Members have more control over their exercise routines, and club operators streamline service levels and facilities.

Membership data collections: Assist development and maintenance of tailored loyalty programs aligned with the needs of every member. The self-service terminals provide information via the interactive digital displays.

Embedded systems: Several functions, including self-check-in, loyalty programs, entertainment and smart training programs. Members can track their fitness progress while having access to customizable music, video and training content, keeping customers engaged and entertained during exercise activity.

RFID Bar code scanners: Allow members to register for classes online or check-in using their membership cards. These embedded systems help to increase attendance, while improving the overall exercise experience.

Interactive multimedia broadcast system: An interactive multimedia system offers the option for customized content, advertisements and new offers. Sustained enthusiasm and entertainment across multiple channels by segment will offset some of the recent at-home emerging threats. Queuing status can be updated, and the fitness centers can display media on digital terminals or multi-display video walls for needs at individual locations.

Indoor air quality (IAQ) monitoring: IAQ captures air information collected by sensors to make indoor air quality management easier in a physical exercise setting. With database capabilities, fitness centers can create air quality analysis reports, reduce personnel costs, reduce energy costs and contribute to achieving a healthy exercise environment. These tools help ensure public health, leading to more satisfied customers, employees and reduced absenteeism.

Platforms: Enlist strategic partners such as Intel to help mitigate some of the technology risk. Joining forces with strategic suppliers will enhance the platform's fitness UI console and iOS/Android OS integrations. The standard open-frame platform solution promises high performance, low power consumption, connectivity and OS support for BYOD Chrome, iOS, Android and Windows. The connected devices deliver synchronized integrations for advances across entertainment (music/video), social media and training/coaching applications.

\section{Conclusion}

Harnessing the power of networks and platforms that fosters an ecosystem of participants will be transformative. A local gym can move from dumbbells to smart tools that help manage demand and capacity with multi-sided market signals. The scenario of fitness clubs illustrates an approach to improve customer engagement, platform journey and participant outcomes. Incorporating new technologies to manage physical and digital assets offers many new opportunities. Recent and emerging innovations alter the customer experience and competitive landscape. Venture capital, private equity and corporate intrapreneur- 
ship will continue to press the frontier of new capabilities and new business models.

\subsection{Platform Adoption and Timing Are Vital}

Catalysts can ignite the business when cultural readiness and new technology enablement coalesce at a critical inflection point.

At a recent Goldman Sachs analyst review of quarterly results, the word "platform" was mentioned 19 times. The technology-based platforms attract sizeable upfront investment, and are expected to generate strong margins going forward. Stephen Scherr, Goldman's CFO said Goldman is applying a platform mentality to innovate, disrupt and automate. The multi-sided platforms introduce new businesses that "operate at scale with small increase in costs as revenues rise (hopefully) exponentially".

\section{Platform Network Effects and Market Computing Adoption for} Mobile Computing

Apple began developing Newton mobile computing devices in 1987 and shipped these devices in 1993. Production was shut down on February 27, 1998 due to market entry that was too early. Sufficient user awareness and acceptance had not yet matured. As shown in Figure 7, the timing for introducing the Palm Pilot was also too early to encounter the ideal conditions of technology, value-derived, user adoption, partner ecosystem and market readiness [18].

Embedding technology such as IoT enables better gym workout sessions that use connected devices for better participant results. As capabilities further evolve, expect to see biometric member check-in and workout equipment that automatically adapts to personal capabilities, needs and thresholds.

The workout experience of the future will enjoy technology to push up ever

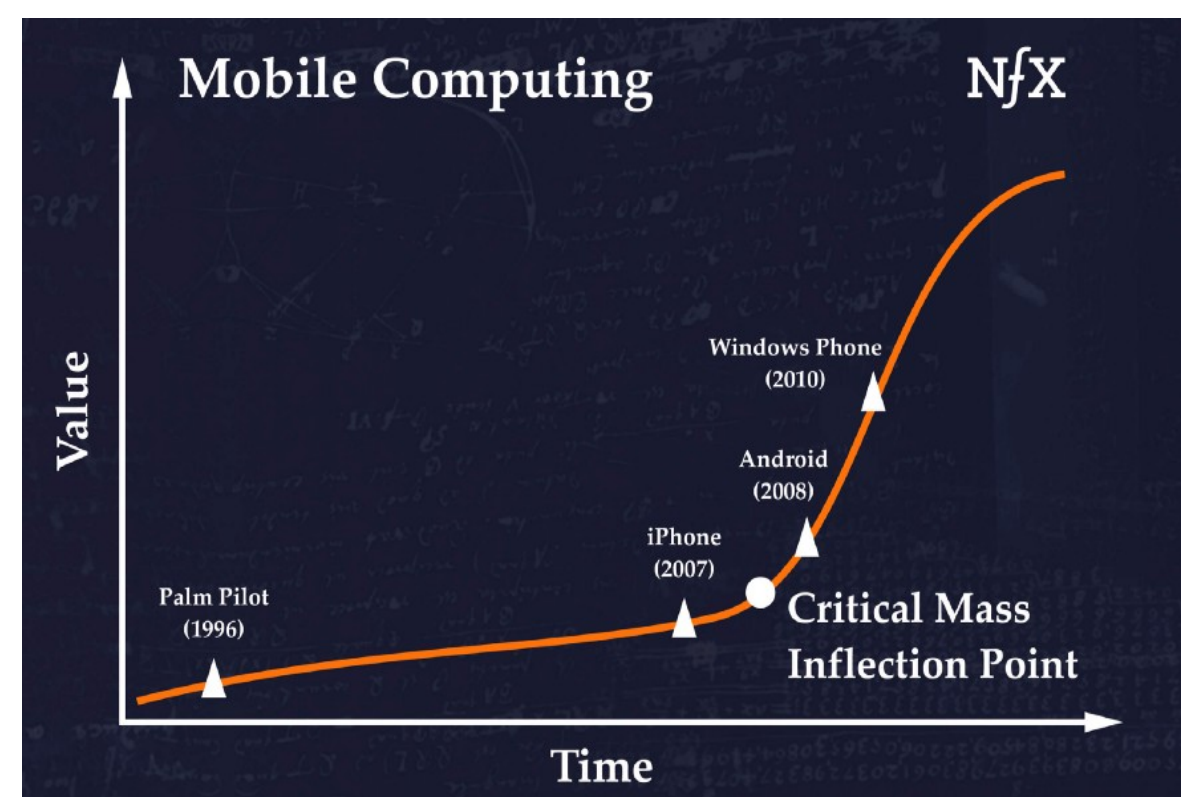

Figure 7. Mobile computing adoption and critical mass inflection point. 
higher. Matching, allocating and clearing automation can also be supplemented with refinements to business rules, peak period management, surge pricing, promotional campaigns, notifications/alerts and related demand management or capacity management arrangements. Taking time to understand the participant persona's, infrastructure cost structures and scaling effects can create additional opportunities to leverage a multi-sided digital platform.

This analysis points to the significance and impact from multi-sided platforms with internal, external and third-party participants. The framework assessed the long-term network effects as more customer and resources transact on a platform's growing eco-system. The convergence of sensor monitoring, GPS, Big Data and Cloud represent advances increasingly available to the fitness industry as well as a wide range of business models and industry sector types. In the history of innovation, we are witnessing today a major inflection point. Several new opportunities are within reach of the creative and bold.

\section{Conflicts of Interest}

The author declares no conflicts of interest regarding the publication of this paper.

\section{References}

[1] Federal Trade Commission (2016) The Sharing Economy: Issues Facing Platforms, Participants \& Regulators. FTC Staff Report, 8.

[2] Smith, A. (2016) Shared, Collaborative and on Demand: The New Digital Economy. https://www.pewinternet.org/2016/05/19/the-new-digital-economy/

[3] Evans, D.S. (2009) How Catalysts Ignite: The Economics of Platform-Based Start-Ups. In: Gawer, A., Ed., Platforms, Markets and Innovation, Edward Elgar Publishing, 345

[4] Zervas, G., Proserpio, D. and Byers, J. (2016) The Rise of the Sharing Economy: Estimating the Impact of Airbnb on the Hotel Industry. Journal of Marketing Research, 54, 687-705. https://doi.org/10.1509/jmr.15.0204

[5] Kenney, M. and Zysman, J. (2016) The Rise of the Platform Economy. Issues in Science and Technology, 32, 61 .

[6] Frenkel, K. and Schor, J. (2017) Putting the Sharing Economy into Perspective. Environmental Innovation and Societal Transitions, 23, 10.

[7] Op. Cit. Evans (2009).

[8] Rochet, J.-C. and Tirole, J. (2003) Platform Competition in Two-Sided Markets. Journal of the European Economic Association, 1, 990-1029. https://doi.org/10.1162/154247603322493212

[9] Ramirez, E., Ohlhausen, K. and McSweeney, T. (2016) The Sharing Economy: Issues Facing Platforms, Participants \& Regulators, 3.

[10] Currier, J. (2019) The Network Effects Manual, NFX.

[11] Evans, D.S. and Schmalense, R. (2008) Markets with Two-Sided Platforms. Issues in Competition Law and Policy. American Bar Association, Antitrust Law, 1.

[12] Op. Cit. Evans (2008).

[13] Evans, D.S. (2011) Interchange Fees: The Economics and Regulation of What Mer- 
chants Pay for Cards. Competition Policy International, 2, 261.

[14] Op. Cit. Evans (2011).

[15] Fisher, C. (2018) Cloud versus On-Premise Computing. American Journal of Industrial and Business Management, 8, 1991-2006. https://doi.org/10.4236/ajibm.2018.89133

[16] Lunden, I. (2016) Salesforce Buys Demandware for $\$ 2.8$ Billion, Taking a Big Step into E-Commerce. TechCrunch.

[17] Rayome, A. (2019) Salesforce Buys Tableau for \$15.7 Billion to Up Its Enterprise Analytics Game. TechRepublic.

[18] Currier, J. (2019) The Network Effects Manual, NFX. Op. Cit. Currier. 


\section{Terminology}

Terminology used in the design, development and operations of multi-sided platforms appears in Table 9.

Table 9. Terminology.

\begin{tabular}{|c|c|}
\hline Term & Description \\
\hline Asset Light & $\begin{array}{l}\text { Minimal capital expenditure on assets can enable the } \\
\text { platform solution to scale and gain market share. An } \\
\text { asset light approach accompanied by a multi-sided } \\
\text { platform can enable higher utilization, ecosystem } \\
\text { growth and network effects. }\end{array}$ \\
\hline COTS & $\begin{array}{l}\text { Commercial Off the Shelf software that requires } \\
\text { configuration but minimal need to code or customize. }\end{array}$ \\
\hline CPQ & $\begin{array}{l}\text { Configure, Price and Quote is central to } \\
\text { Digital Commerce. }\end{array}$ \\
\hline Digital Platform & $\begin{array}{l}\text { An online structure that enables a range of human } \\
\text { activity which creates value in the economy. }\end{array}$ \\
\hline Endpoint & $\begin{array}{l}\text { The user device is an Endpoint. Endpoint management } \\
\text { provides protection, backup, fault tolerance, restoration } \\
\text { and compliance across all user devices and encrypted } \\
\text { data storage. }\end{array}$ \\
\hline Hybrid Cloud & $\begin{array}{l}\text { A mix of on-premise, private cloud and } 3^{\text {rd }} \text { party public } \\
\text { cloud with orchestration between public and private. }\end{array}$ \\
\hline IaaS & $\begin{array}{l}\text { Infrastructure as a service. Also known as utility } \\
\text { computing or cloud hosting. }\end{array}$ \\
\hline Machine Learning & $\begin{array}{l}\text { Handles large datasets to generate new insights about } \\
\text { customers, products, plants, prices, supply chain, etc. }\end{array}$ \\
\hline Multi-Sided Market & $\begin{array}{l}\text { Roughly defined as markets in which a platform enables } \\
\text { interactions between participants to get the sides "on } \\
\text { board", with appropriately charges to each side. } \\
\text { Platforms may service all sides to transact, match or } \\
\text { auction available resources and products to customers. }\end{array}$ \\
\hline MVP & $\begin{array}{l}\text { Minimum Viable Product is released earlier than } \\
\text { traditional Waterfall approach to accelerate time to } \\
\text { value and leverage Agile principles which include } \\
\text { stakeholder input. }\end{array}$ \\
\hline PaaS & Platform as a Service. \\
\hline Platform Economy & $\begin{array}{l}\text { Also known as "the creative economy", "the sharing } \\
\text { economy", "the gig economy", or "the peer economy". }\end{array}$ \\
\hline SDP & $\begin{array}{l}\text { Strategic Digital Platforms include offerings available } \\
\text { from a range of suppliers such as Salesforce.com, } \\
\text { Oracle Digital Commerce, SAP, ServiceNow, etc. }\end{array}$ \\
\hline TLV & Total Lifetime Value of Customer \\
\hline VoC & $\begin{array}{l}\text { Voice of Customer helps capture key requirements } \\
\text { and user experience during application development } \\
\text { and ongoing support. }\end{array}$ \\
\hline XaaS & Anything as a Service. \\
\hline
\end{tabular}

